JGG 2021;69:45-52

doi: $10.36150 / 2499-6564-340$

\title{
Quality of life, hospitalisation and sarcopenia among the elderly: a systematic review
}

\author{
Adha Nawawi ${ }^{1,2}$, Maria Justine ${ }^{1}$, Rizah Mazzuin Razali ${ }^{2}$ \\ ${ }^{1}$ Centre for Physiotherapy Studies, Faculty of Health Sciences, Universiti Teknologi MARA \\ Selangor, Puncak Alam Campus, 42300 Puncak Alam, Selangor Malaysia; ${ }^{2}$ Kuala Lumpur \\ Hospital, Ministry of Health, Malaysia
}

Introduction. Sarcopenia has been demonstrated to affect the quality of life (QoL) of hospitalised elderly. However, no convincing evidence for the best method for measuring sarcopenia in hospitalised elderly is available. The current review aims to investigate the common outcome measures used to measure QoL and sarcopenia in hospitalised elderly. Method. A systematic search of the literature was conducted manually and by using databases, such as Scopus, Web of Science, and PubMed, with various search terms, such as "quality of life," "health-related quality of life", "elderly", "older persons", "sarcopenia", and "sarcopenic". Two researchers independently assessed the studies for eligibility. Studies included in the review were written in the English language and indexed journals published between 2015 and 2019.

Received: June 15, 2019

Accepted: April 22, 2020

\section{Correspondence \\ Maria Justine \\ Centre for Physiotherapy Studies, Faculty of Health Sciences, Universiti Teknologi MARA Selangor, Puncak Alam Campus, 42300 Puncak Alam, Selangor Malaysia \\ E-mail: maria205@uitm.edu.my}

\section{Conflict of interest}

The Authors declare no conflict of interest

How to cite this article: Nawawi A, Justine M, Mazzuin Razali R. Quality of life, hospitalisation and sarcopenia among elderly: a systematic review. Journal of Gerontology and Geriatrics 2021;69:45-52. https://doi.org/10.36150/2499-6564-340

C Copyright by Società Italiana di Gerontologia e Geriatria (SIGG)

\section{(c) (1) () $(-)$}

\section{OPEN ACCESS}

This is an open access article distributed in accordance with the CC-BY-NC-ND (Creative Commons Attribution-NonCommercial-NoDerivatives 4.0 International) license. The article can be used by giving appropriate credit and mentioning the license, but only for non-commercial purposes and only in the original version. For further information: https://creativecommons.org/licenses/by-nc-nd/4.0/deed.en
Results. A total of 400 studies were retrieved; among which, 5 articles were included in the review. The review found that various sarcopenia measures were applied as follows: two studies, skeletal muscle index; one study, muscle cross-sectional area; one study, SARC-F (sluggishness, assistance in walking, rise from a chair, climb stairs, falls) questionnaire; and one study, the algorithm of the European Working Group for Sarcopenia in Older People. The outcome measures for QoL that were used in the studies included the 36-item short-form survey, EuroQoL-5 dimension, Kidney Disease Quality of Life-Short Form, and CASP-12 (control, autonomy, self-realization, pleasure) scale. Mixed results were found in the relationship of QoL with hospitalisation and sarcopenia.

Conclusions. Inconsistent findings were found for the relationship between QoL and sarcopenia probably because of the different measures used to assess sarcopenia and QoL of the elderly. The results highlight the importance of conducting a further study on QoL among the elderly with sarcopenia, particularly those who were hospitalised using the currently recommended tool for assessing sarcopenia. Such research may promote patient-centered care and improve QoL by incorporating the concept of QoL into geriatric rehabilitation.

Key words: elderly, hospitalisation, quality of life, sarcopenia

\section{INTRODUCTION}

With the increasing aging population, sarcopenia may become a major issue that requires special attention among healthcare providers. Sarcopenia is a 
muscular disease characterised by low muscle strength surpassing the role of low muscle mass as a principal element ${ }^{1}$. This condition affects the quality of life (QoL) and increases the mortality rate among the elderly ${ }^{2}$. Elderly with progressive sarcopenia may exhibit poor functional status, which affects their QoL, particularly elderly hospitalised due to chronic illnesses. Various studies have shown that the prevalence of sarcopenia is critically high among hospitalised elderly. Approximately $21.8 \%$ of sarcopenia has been reported in a multispecialty hospital ${ }^{3}$, and another recent study found a prevalence of sarcopenia reaching as high as $31 \%$ in the acute geriatric ward. Elderly with sarcopenia who are hospitalised maybe exposed to more hazards than those without sarcopenia ${ }^{5}$. Few studies have argued that the surrounding environment in a hospital may cause various complications in relation to sarcopenia ${ }^{6-8}$.

Regardless of the current status of sarcopenia and the comorbidity of the elderly, optimal QoL should be the ultimate aim of healthcare provision to be delivered to vulnerable individuals. QoL is defined by the World Health Organization as an individual's acuity in life in relation to their culture and value systems and relative to their goals, expectations, standards, and concerns ${ }^{9}$. Despite the increasing interest in studying sarcopenia, limited studies have focused on sarcopenia among the hospitalized elderly ${ }^{10-14}$. This could be because, sarcopenia has been inconsistently defined or determined as various outcome measures have been applied to different settings for the elderly population. In addition, QoL among the elderly with sarcopenia is inconsistently determined ${ }^{12,13,15}$. The results of previous studies may be inapplicable to the hospitalised elderly due to the presence of comorbidities and progressive functional decline. Therefore, further studies are necessary to understand how QoL can be affected by the presence of sarcopenia among the elderly who are at risk of hospitalisation. This understanding may guide the incorporation of QoL into promoting patient-centered care as part of a geriatric rehabilitation program.

This review attempts to answer the following research questions. 1) What are the commonly used outcome measures for assessing sarcopenia and QoL for hospitalised elderly? 2) Is there a relationship between QoL and sarcopenia among the elderly who were hospitalised or at risk of hospitalisation? Accordingly, this study reviews the existing literature to describe the current state of QoL of elderly with sarcopenia who were hospitalised or at risk of hospitalisation.

\section{METHOD}

\section{LITERATURE SEARCH}

A thorough search for eligible studies was initiated by entering relevant keywords in related databases, such as Scopus, Web of Science, and PubMed, and via manual search, as shown in Table I. The review process was reported on the basis of the outline stated in the Preferred Reporting Items for Systematic Reviews and Meta-Analyses (PRISMA) protocols (Fig. 1).

PRISMA was applied because it offers three exclusive advantages: 1) it defines clear research questions, permitting a systematic research; 2) it identifies the inclusion and exclusion criteria; and 3 ) it attempts to examine a large database of scientific literature in a defined time ${ }^{16}$. The PRISMA statement allows for a rigorous search of terms related to QoL, hospitalisation, and sarcopenia among the elderly.

\section{THE DATA SEARCH}

Data search involved four phases.

Phase 1 - Identification: the relevant keywords listed in Table I were searched to identify articles in the database. The search was restricted to articles published from 2015 to 2019. The keywords used in the search process were identified during this phase.

Phase 2 - Screening: in this phase, the selection criteria (Tab. II) were used to find suitable and related articles in the review process. First, only articles with empirical data were selected in terms of literature type. Review articles, book series, books, chapters in book, and conference proceedings were excluded. Second, to avoid any misunderstanding and difficulty in translation, the search excluded

Table I. Keywords and searching information strategy.

\begin{tabular}{|c|c|}
\hline Databases & Key words used \\
\hline Scopus & $\begin{array}{l}\text { TITLE-ABS-KEY (("Quality of life” OR “Health-related quality of life” OR health) AND (hospitali*ed OR hospitali*ation) AND } \\
\text { (elderly OR aged OR seniors OR geriatric OR “Older person”) AND (sarcopenia OR sarcopenic)) }\end{array}$ \\
\hline Web of Science & 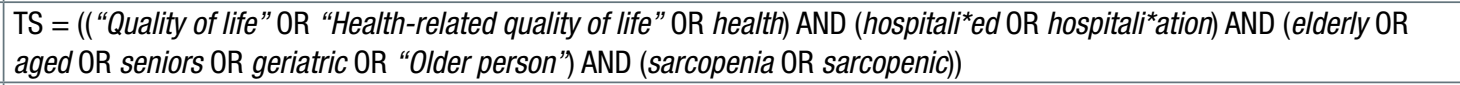 \\
\hline Pubmed & $\begin{array}{l}\text { ((((((“quality of life") OR "health-related quality of life”) OR health)) AND ((((hospitalised) OR hospitalised) OR hospitalisation) } \\
\text { OR hospitalisation)) AND (((((elderly) OR aged) OR seniors) OR geriatric) OR “Older person”)) AND ((sarcopenia) OR sarcopenic) }\end{array}$ \\
\hline
\end{tabular}




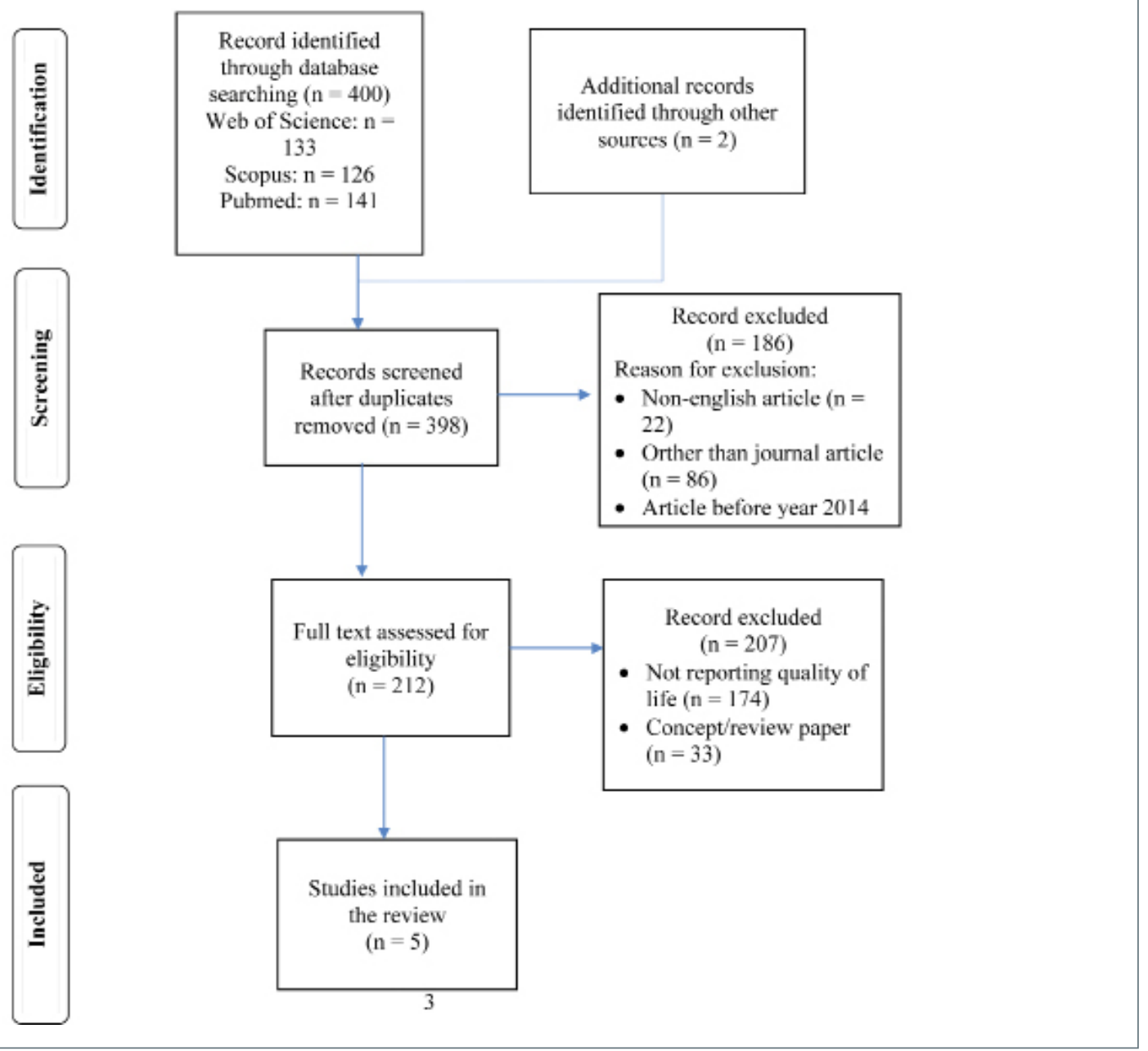

Figure 1. A PRISMA flow diagram for the systematic review process.

Table II. Inclusion and exclusion criteria.

\begin{tabular}{|l|l|l|}
\hline Criterion & \multicolumn{1}{|c|}{ Eligibility } & \multicolumn{1}{c|}{ Exclusion } \\
\hline Literature type & Indexed journal (research articles) & $\begin{array}{l}\text { Non-indexed journals, systematic review journals, chapter in book, } \\
\text { conference proceeding }\end{array}$ \\
\hline Language & English & Non-English \\
\hline Time-line & Between 2015-2019 & $<2014$ \\
\hline
\end{tabular}

non-English publications and focused only on articles published in English. Third, a period of 5 years was set as the timeline (between 2015 and 2019), which is adequate to cover the evolution of research and related publications.

Phase 3 - Eligibility: the selected articles were reviewed in this phase, and any articles that did not meet the selection criteria were excluded.

Phase 4 - Articles are ready for analysis: articles that met the inclusion and exclusion criteria were prepared for analysis.

\section{Data ANALYTIC Strategy}

The remaining articles were assessed and analyzed. Specific studies that responded to the formulated questions were evaluated. The data were extracted by first reading the abstracts, and then the full articles (in-depth) were read to identify appropriate themes and subthemes. All the authors developed the research review approach. 
Initial screening was undertaken by one researcher (AN) and then checked by another (MJ). Different views on inclusion were discussed until an agreement was reached. One of the researchers (AN) extracted the following data from the selected studies: study sample, measurements, recommendations, and major results. The extracted data were checked and corrections were made where necessary by the other researcher (RMR). All the researchers contributed to the synthesis of the data.

\section{RESULTS}

A total of 400 studies were identified through electronic database and manual searches (Fig. 1). Among these studies, 2 duplicates were removed. Therefore, 398 articles were screened on the basis of their titles and abstracts by two independent reviewers. Only 5 studies met the inclusion criteria (Tab. III). All the studies were from 2015 to 2018. The studies were performed from multiple regions (USA, Canada, Brazil, Korea, and Taiwan).
The mean age of the participants differed. The mean age in two studies was below 60 years old ${ }^{17,18}$, while the mean in the other studies was above 60 years old. The sample size remarkably varied from 170 to 4937 participants. The participants for the selected studies were non-institutionalised elderly with various conditions ${ }^{19,20}$, one study on end-stage liver disease ${ }^{18}$, one study on transplant candidates ${ }^{17}$, and one study on the elderly with maintenance dialysis ${ }^{21}$.

The diagnosis of sarcopenia varied among the studies. Two studies identified sarcopenia through the skeletal muscle index ${ }^{18,19}$. One study used muscle cross-sectional area ${ }^{17}$, and another study used the SARC-F (sluggishness, assistance in walking, rise from a chair, climb stairs, falls) questionnaire ${ }^{13}$. Another study applied the algorithm of the European Working Group for Sarcopenia in Older People (EWGSOP) ${ }^{21}$. The outcome measures for QoL included the 36-item short-form survey (SF 36) ${ }^{17,18}$, EuroQoL-5 dimension (EQ-5D) ${ }^{19}$, Kidney Disease Quality of Life-Short Form ${ }^{21}$, and CASP-12 (control, autonomy, self-realization, pleasure) scale ${ }^{20}$.

Table III. Articles selected for analysis.

\begin{tabular}{|c|c|c|c|c|c|c|c|c|}
\hline Authors & Design & Country & $\begin{array}{l}\text { Sample } \\
\text { size }\end{array}$ & $\begin{array}{c}\text { Mean age } \\
\text { (years) }\end{array}$ & Participants & $\begin{array}{c}\text { Measures } \\
\text { of } \\
\text { sarcopenia }\end{array}$ & $\begin{array}{c}\text { Quality } \\
\text { of life } \\
\text { measures }\end{array}$ & $\begin{array}{l}\text { Other } \\
\text { tests }\end{array}$ \\
\hline $\begin{array}{l}\text { Yadav et } \\
\text { al. }{ }^{18}\end{array}$ & $\begin{array}{c}\text { Not } \\
\text { mentioned }\end{array}$ & USA & $\begin{array}{l}213 \\
\text { Male: } 129 \\
\text { Female: } \\
84\end{array}$ & $55.3 \pm 8.6$ & $\begin{array}{l}\text { Patients with } \\
\text { End Stage Liver } \\
\text { Disease (ESLD) } \\
\text { listed for Liver } \\
\text { Transplant (LT). }\end{array}$ & $\begin{array}{c}\text { Skeletal } \\
\text { Muscle Index }\end{array}$ & SF36 & $\begin{array}{c}\text { Six Minute } \\
\text { Walk Test } \\
\text { (6MWT) }\end{array}$ \\
\hline Wu et al. ${ }^{20}$ & $\begin{array}{l}\text { Prospective } \\
\text { cohort study, } \\
\text { random } \\
\text { sampling }\end{array}$ & Taiwan & $\begin{array}{c}670 \\
\text { Male: } 340 \\
\text { Female: } \\
330\end{array}$ & $76.1 \pm 6.36$ & $\begin{array}{l}\text { Elderly resident } \\
\text { who had } \\
\text { undergone } \\
\text { annual health } \\
\text { examination. }\end{array}$ & $\begin{array}{c}\text { SARC-F } \\
\text { questionnaire }\end{array}$ & $\begin{array}{c}\text { CASP-12 } \\
\text { scale (control, } \\
\text { autonomy, } \\
\text { self-realization, } \\
\text { pleasure } \\
\text { (control, } \\
\text { autonomy, } \\
\text { self-realization, } \\
\text { pressure) }\end{array}$ & $\begin{array}{c}\text { Brief } \\
\text { Symptom } \\
\text { Rating Scale } \\
\text { (BSRS) }\end{array}$ \\
\hline $\begin{array}{l}\text { Rozenberg } \\
\text { et al. }{ }^{17}\end{array}$ & $\begin{array}{l}\text { Retrospective } \\
\text { cohort study }\end{array}$ & Canada & $\begin{array}{c}527 \\
\text { Male: } 283 \\
\text { Female: } \\
244\end{array}$ & $\begin{array}{c}\text { Median age: } 55 \text { IQR } \\
(42-62)\end{array}$ & $\begin{array}{c}527 \text { lung } \\
\text { transplant } \\
\text { candidates }\end{array}$ & $\begin{array}{l}\text { Muscle cross } \\
\text { sectional area } \\
\text { (CSA) }\end{array}$ & SF36 & $\begin{array}{l}\text { Six Minute } \\
\text { Walk Test } \\
(6 \mathrm{MWT})\end{array}$ \\
\hline Sun et al. ${ }^{19}$ & $\begin{array}{l}\text { Cross- } \\
\text { sectional } \\
\text { study }\end{array}$ & Korea & $\begin{array}{c}4,937 \\
\text { Male: } \\
2160 \\
\text { Female: } \\
2777\end{array}$ & $\begin{array}{c}\text { Men = } \\
72.6 \pm 0.58 \\
\text { Women }= \\
72.1 \pm 0.94\end{array}$ & $\begin{array}{l}\text { Older people who } \\
\text { underwent a DXA } \\
\text { scan }\end{array}$ & $\begin{array}{c}\text { Skeletal } \\
\text { Muscle Index }\end{array}$ & $\begin{array}{c}\text { EuroQoL-5 } \\
\text { Dimension (EQ- } \\
\text { 5D) }\end{array}$ & - \\
\hline $\begin{array}{l}\text { Giglio et } \\
\text { al. }{ }^{21}\end{array}$ & $\begin{array}{c}\text { Multicenter } \\
\text { observational } \\
\text { longitudinal } \\
\text { study }\end{array}$ & Brazil & $\begin{array}{c}170 \\
\text { Male: } 111 \\
\text { Female: } \\
59\end{array}$ & $70 \pm 7.6$ & $\begin{array}{c}\text { Elderly on } \\
\text { Maintenance } \\
\text { Dialysis }\end{array}$ & $\begin{array}{c}\text { European } \\
\text { Working Group } \\
\text { for Sarcopenia } \\
\text { in Older People } \\
\text { (EWGSOP) }\end{array}$ & $\begin{array}{c}\text { Kidney Disease } \\
\text { Quality of Life- } \\
\text { Short Form }\end{array}$ & $\begin{array}{l}\text { Nutritional } \\
\text { status (Body } \\
\text { Fat Index) }\end{array}$ \\
\hline
\end{tabular}


Additional parameters, namely, the six-minute walk test $(6 \mathrm{MWT}){ }^{17,18}$, brief symptom rating scale (BSRS) ${ }^{20}$, and nutritional status using body fat index ${ }^{21}$, were included in some studies.

\section{QOL AND HOSPITALISATION AMONG ELDERLY WITH SARCOPENIA}

From Table IV, mixed results were obtained on the relationships of QoL with hospitalisation and sarcopenia among the elderly. Yadav et al. ${ }^{18}$ found no significant relationship between QoL and the physical component score $(p=0.71)$ and mental component score $(p=0.66)$ among hospitalised elderly with and without sarcopenia. Similarly, Rozenberg et al. ${ }^{17}$ reported that muscle cross-sectional area was not associated with QoL but with hospital stay.

Giglio et al. ${ }^{21}$ found that low muscle strength, as one of the indicators for sarcopenia, was associated with the worse QoL domains based on the Kidney Disease Quality of Life-Short Form. In addition, they also found that low muscle strength and the presence of sarcopenia were associated with risk of hospitalisation. Sun et al. ${ }^{19}$ reported a significant association between sarcopenia and worse QOL in men and women with sarcopenia. A significant difference was found in EQ5D among hospitalised elderly with and without sarcopenia for both males and females $(p=0.01$ and 0.03 , respectively). Wu et al. ${ }^{20}$ demonstrated that sarcopenia was associated with overall hospitalisation in 4 years and QoL in years 2 and 4 during the study period.

\section{DISCUSSION}

To the authors' knowledge, this study is the first attempt to systematically review sarcopenia and QoL among hospitalised elderly. The results of the review showed inconsistent findings on the current state of sarcopenia, QoL, and hospitalisation of the elderly. Studies that may answer the current research questions are limited. Only five studies satisfied the inclusion criteria probably due to the restricted inclusion criteria, i.e., only studies from 2014 to 2019 were included, and the keyword entered should include hospitalisation. This review focuses on hospitalised elderly because of the limited studies on this group. In addition, sarcopenia has been regarded as a new geriatric "giant" in recent years because of its high prevalence ${ }^{1,22,23}$.

The studies included in this review were diverse in terms of design (cohort, retrospective, cross-sectional, and observational longitudinal studies), included participants (patients with end-stage liver disease, elderly on maintenance dialysis, and elderly individuals), types of outcome measure, and methods for diagnosing

Table IV. Analysis of quality of life and hospitalisation in elderly with sarcopenia.

\begin{tabular}{|c|c|c|}
\hline Authors & Quality of life measures & Summary of findings \\
\hline Yadav et al. ${ }^{18}$ & HRQoL, SF36 questionnaire & $\begin{array}{l}\text { Sarcopenia did not correlate with PCS score } \\
(r=0.03, p=0.71) \text { and MCS score }(r=0.03 \text {, } \\
p=0.66)\end{array}$ \\
\hline Wu et al. ${ }^{20}$ & CASP-12 Chinese Taiwan version & $\begin{array}{l}\text { Sarcopenia was associated with overall } \\
\text { hospitalisation in } 4 \text { years }(p=0.004), Q 0 L \text { in year } 2 \\
(p<0.01) \text { and } Q 0 L \text { in year } 4(p<0.001) \text { during the } \\
\text { study period. }\end{array}$ \\
\hline Rozenberg et al. ${ }^{17}$ & HRQoL, SF36 questionnaire & $\begin{array}{l}\text { Muscle cross-sectional area (CSA) was associated } \\
\text { with pre-transplant 6MWD but not health-related } \\
\text { QoL. } \\
\text { Muscle CSA (per } 10 \mathrm{~cm} 2 \text { difference) was associated } \\
\text { with shorter hospital stay [0.7 median days } 95 \% \mathrm{Cl} \\
(0.2-1.3)] \text {. }\end{array}$ \\
\hline Giglio et al. ${ }^{21}$ & Kidney disease quality of life-short form & $\begin{array}{l}\text { Low muscle strength was associated with worse } \\
\text { QoL domains ( } \mathrm{p}<0.05) \text {. } \\
\text { Low muscle strength (RR } 1.92,95 \% \mathrm{Cl}=1.38- \\
2.57 \text { ) and with sarcopenia (RR } 2.07) 95 \% \\
\mathrm{Cl}=1.48-2.88 \text { ) were associated with a higher RR } \\
\text { for hospitalisation events, even after adjusting for } \\
\text { age, gender, dialysis vintage and DM. }\end{array}$ \\
\hline Sun et al. ${ }^{19}$ & EuroQoL-5 dimension (EQ-5D) & $\begin{array}{l}\text { After adjusting for age, BMI and total body fat } \\
\text { mass, there was a significant association between } \\
\text { sarcopenia and worse EQ-VAS and EQ-5D index } \\
\text { scores in men and women. }\end{array}$ \\
\hline
\end{tabular}


sarcopenia. These diversities may have potentially contributed to the inconsistency in the findings for QoL and hospitalisation among the elderly with sarcopenia. The presence of different comorbidities and the level of functions among the hospitalised may explain the diversity in patients recruited for a specific study because patients with established diseases may also present with various geriatric syndromes. The limited studies among hospitalised elderly can be due to the complex process in which the awareness and integrity of the researcher is the key to upholding the principle of non-exploitation ${ }^{24}$. Furthermore, previous elderly care was focused on disease management rather than improving the patient's functional status ${ }^{25}$ because sarcopenia is considered a limiting factor for the ability to function optimally.

Reports obtained from this review showed a mixed result of QoL and hospitalisation among elderly with sarcopenia. The variation may be due to the considerable differences in the sample size in the reviewed studies. Studies by Sun et al. ${ }^{19}$ and Wu et. ${ }^{20}$ had positive findings because of the large sample size. Adequate sample size is required to distinguish meaningful differences ${ }^{26}$. Two recent studies found that QoL is negatively associated with sarcopenia ${ }^{27,28}$, indicating that the occurrence of sarcopenia may deteriorate QoL of the elderly. However, this finding has to be considered with precaution because whether the presence of sarcopenia has already occurred even before the elderly were hospitalized or whether sarcopenia can be influenced by other factors remains unknown. Furthermore, the elderly may perceive their QoL as poor while in the hospital because the hospital environment and their current disease condition may influence their psychological well-being. For example, one study showed that depression is highly prevalent among hospitalised elderly ${ }^{29}$. Thus, the measurement of QoL should consider a more sensitive tool that can accurately measure any changes within a short duration.

The current review also found that tools for measuring QoL were not uniform and varied among the studies. Giglio et al. ${ }^{14}$ used a disease-specific for QoL measure, whereas the other studies used generic tools. The studies included in this review were conducted in different countries with diverse levels of income. Korea and Taiwan were categorised as low-income countries, while Brazil, USA, and Canada were categorized as middle/upper-income countries. These income categories may result in differences in the socioeconomic perspective among the participants of the reviewed studies, which in turn, influence their sarcopenia level ${ }^{30}$. The measurement of QoL in nearly all the reviewed studies were performed only once, except for Wu et al. ${ }^{20}$ who measured QoL twice on years 2 and 4. Repeated measures may be useful to follow up the elderly with sarcopenia to determine whether their QoL will improve or may further deteriorate with time. In addition, following up the measurement of $\mathrm{QoL}$ is rational because the elderly may further deteriorate not because of the changes in the physical environment but also due to progressive aging changes and psychological effects after hospitalisation. A previous study showed that a high QoL upon admission is associated with low risk of mortality and functional decline at 3 months after admission ${ }^{31}$.

The different methods for assessing sarcopenia may also lead to the inconsistent findings in QoL and hospitalisation for the elderly. With an enhanced understanding on the identification of sarcopenia, a new algorithm by EWGSOP2 was introduced recently ${ }^{1}$. This algorithm outlined the process for screening and assessing sarcopenia using the SARC-F questionnaire, muscle strength, muscle quality, and physical performance to determine the presence and severity of sarcopenia. The new algorithm may be the best tool for measuring sarcopenia among hospitalised elderly because the components of its indices are pertinent to the functional status of the elderly. However, none of the studies included in the current review have fulfilled the EWGSOP2 algorithm.

\section{IMPLICATIONS AND LIMITATIONS OF THE STUDY}

From the findings of the current systematic review, the assessment of sarcopenia should follow the recommended tools and measurements in the current guideline of the EWGSOP2 algorithm. We also recommend that the measurement of QoL should be repeated at least two times after hospital discharge to detect any changes, particularly in the early episode. In addition, a more sensitive QoL measure should be implemented for the frail elderly. For example, the use of EQ-5D has been shown to provide means of risk stratification and may ultimately guide individuals, their families, and professionals in making treatment decisions during hospitalisation ${ }^{31}$.

One of the limitations of this study is the small number of studies (only five related reports) included in the review. Thus, additional studies on QoL are necessary to evaluate QoL among hospitalised elderly with sarcopenia. Then, meta-analysis should be performed to examine the effect or trend of current information on hospitalised and post-hospitalised elderly.

\section{CONCLUSIONS}

This systematic review shows that there is a lack of studies regarding QoL and hospitalisation among the 
elderly with sarcopenia. In the studies that were reviewed, there were inconsistent findings on QoL among hospitalised elderly. This could be due to differences in the study design, participants included, types of outcome measure and methods for assessing sarcopenia. Further studies are needed using the current classification for sarcopenia and valid tools for measuring QoL.

\section{FUNDING STATEMENT}

This study was self-funded as this is part of a Master student's requirement for thesis completion.

\section{References}

1 Cruz-Jentoft AJ, Baeyens JP, Bauer JM, et al. Sarcopenia: European consensus on definition and diagnosis. Age Ageing 2018;39:412-23. https://doi.org/10.1093/ageing/ afz046

2 Beaudart C, Rizzoli R, Bruyere O, et al. Sarcopenia: burden and challenges for public health. Arch Public Health 2014;72:1-8. https://doi.org/10.1186/2049-3258-72-45

3 Martinezatista AKMS, Gomes IB, et al. Frequency of sarcopenia and associated factors among hospitalised elderly patients pathophysiology of musculoskeletal disorders. BMC Musculoskelet Disord 2015;16:1-7.

4 Hao Q, Hu X, Xie L, et al. Prevalence of sarcopenia and associated factors in hospitalised older patients: a crosssectional study. Australas J Ageing 2018;37:62-7. https:// doi.org/10.1111/ajag.12492

5 Montano-loza AJ, Meza-junco J, Baracos VE, et al. Severe muscle depletion predicts postoperative length of stay but is not associated with survival after liver transplantation. Liver Transplantation 2014;20:640-8. https://doi. org/10.1002/lt.23863

6 Cosqueric G, Sebag A, Ducolombier C, et al. Sarcopenia is predictive of nosocomial infection in care of the elderly. Br J Nutr 2006;96:895-901. https://doi.org/10.1017/ bjn20061943

7 Liu P, Hao Q, Hai S, et al. Sarcopenia as a predictor of all-cause mortality among community-dwelling older people: a systematic review and meta-analysis. Maturitas 2017;103:16-22. https://doi.org/10.1016/j.maturitas.2017.04.007

8 Marengoni A, Winblad B, Karp A, et al. Prevalence of chronic diseases and multimorbidity among the elderly population in Sweden. Am J Public Health 2018;98:1198200.

9 WHOQOL: measuring quality of life [cited 12 June 2019]. In: World Health Organization (https://www.who.int/healthinfo/survey/whoqol-qualityoflife/en).

10 Bruyère $\mathrm{O}$, Beaudart $\mathrm{C}$, Ethgen $\mathrm{O}$, et al. The health economics burden of sarcopenia: a systematic review. Maturitas 2018;119:61-9. https://doi.org/10.1016/j.maturitas.2018.11.003

11 Kamiya K, Hamazaki N, Matsuzawa R, et al. Sarcopenia: prevalence and prognostic implications in elderly patients with cardiovascular disease. J Cachexia Sarcop Muscle 2017;2:1-13.

12 Larissa A, Marques P, Confortin SC, et al. Quality of life associated with handgrip strength and sarcopenia: EpiFloripa Aging Study. Arch Gerontol Geriatr 2019;81:234-9. https://doi.org/10.1016/j.archger.2018.12.015

13 Silva Neto LS, Karnikowski MG, et al. Association between sarcopenia and quality of life in quilombola elderly in Brazil. Int J Gen Med 2016;9:89-97. https://doi.org/10.2147/ IJGM.S92404

14 Verlaan S, Aspray TJ, Bauer JM, et al. Nutritional status, body composition, and quality of life in community dwelling sarcopenic and non-sarcopenic older adults: a case-control study. Clin Nutr 2017;36:267-74. https://doi. org/10.1016/j.clnu.2015.11.013

15 Nipp RD, Fuchs G, El-Jawahri A, et al. Sarcopenia is associated with quality of life and depression in patients with advanced cancer. Oncologist 2018;23:97-104. https://doi. org/10.1634/theoncologist.2017-0255

16 Sierra-Correa PC, Cantera Kintz JR. Ecosystem-based adaptation for improving coastal planning for sea-level rise: a systematic review for mangrove coasts. Marine Policy 2015;51:385-93.

17 Rozenberg D, Mathur S, Herridge M, et al. Thoracic muscle cross-sectional area is associated with hospita length of stay post lung transplantation: a retrospective cohort study. Transpl Int 2017;30:713-24. https://doi. org/10.1111/tri.12961

18 Yadav A, Chang YH, Carpenter S, et al. Relationship between sarcopenia, six-minute walk distance and health-related quality of life in liver transplant candidates. Clin Transplant 2015;29:134-41. https://doi.org/10.1111/ctr.12493

19 Sun DS, Lee H, Yim HW, et al. The impact of sarcopenia on health-related quality of life in elderly people: Korean National Health and Nutrition Examination Survey. Korean J Intern Med 2017;34:877-84. https://doi.org/10.3904/ kjim.2017.182

20 Wu TY, Liaw CK, Chen FC, et al. Sarcopenia screened with SARC-F Questionnaire is associated with quality of life and 4-year mortality. J Am Med Dir Assoc 2016;17:1129-35. https://doi.org/10.1016/j.jamda.2016.07.029

21 Giglio J, Kamimura MA, Lamarca F, et al. Association of sarcopenia with nutritional parameters, quality of life, hospitalisation, and mortality rates of elderly patients on hemodialysis. J Ren Nutr 2018;28:197-207. https://doi. org/10.1053/j.jrn.2017.12.003

22 Hassan EB, Duque G. Osteosarcopenia: a new geriatric syndrome. Aust Fam Physician 2019;46:849-53.

23 Morley JE. Frailty and sarcopenia: the new geriatric giants. Rev Inves Clin 2016;68:59-67.

24 Harris R, Dyson E. Recruitment of frail older people to research: lessons learnt through experience. J AdV Nurs 2001;36:643-51. https://doi.org/10.1046/j.13652648.2001.02029.x

25 Fougère $B$, Morley JE, Arai $H$, et al. Precision medicine: the future management of geriatric conditions. J Nutr Health Aging 2018:1-4. https://doi.org/10.1007/s12603-018-1045-1 
26 Jean Biau D, Kerneis S, Porcher R. Statistics in brief: the importance of sample size in the planning and interpretation of medical research. Clin Orthop Relat Res 2008;466:2282-92. https://doi.org/10.1007/s11999-0080346-9

27 Manrique-espinoza B, Salinas-rodríguez A, Rosas-carrasco O, et al. Sarcopenia is associated with physical and mental components of health-related quality of life in older adults. J Am Med Dir Assoc 2019;18:636.e1-636.e5. https://doi.org/10.1016/j.jamda.2017.04.005

28 Marques LP, Confortin SC, Ono LM, et al. Quality of life associated with handgrip strength and sarcopenia: EpiFloripa Aging Study. Arch Gerontol Geriatr 2019;81:234-9. https://doi.org/10.1016/j.archger.2018.12.015
29 Alamri SH, Bari Al, Ali AT. Depression and associated factors in hospitalized elderly: a cross-sectional study in a Saudi teaching hospital. Ann Saudi Med 2017;37:122-9. https://doi.org/10.5144/0256-4947.2017.122

30 Dorosty A, Arero G, Chamar M, et al. Prevalence of sarcopenia and its association with socioeconomic status among the elderly in Tehran. Ethiop J Health Sci 2016;26:389-96. https://doi.org/10.4314/ejhs.v26i4.11

31 Parlevliet JL, MacNeil-Vroomen J, Buurman BM, et al. Health-related quality of life at admission is associated with postdischarge mortality, functional decline, and institutionalization in acutely hospitalized older medical patients. J Am Geriatr Soc 2016;64:761-8. https://doi.org/10.1111/ jgs. 14050 